\title{
Real Time Digital Signal Processing and Measurement Method for Electromagnetic Compatibility Verification into the Ships
}

\author{
M. Bakkali ${ }^{1,2}$, C. Mascareñas-Perez-Iñigo ${ }^{2}$ \\ ${ }^{I}$ Control and Communication Department, Air Thermodynamics Division, CIAT, Córdoba (Spain) \\ ${ }^{2}$ Departamento de Ciencias y Técnicas de la Navegación, Cadix University, Cádiz, (Spain) \\ medcasem@hotmail.com -mbakkali@grupociat.es / carlos.mascarenas@uca.es
}

\begin{abstract}
In this paper, we present a new Electromagnetic Compatibility (EMC) measurement and verification system for ships, based on real time digital signal processing techniques, in combination with a VLF-UHF receiver. We programmed all the algorithms for the systems, in order to have reliable software, known, expandable and intuitive. The basis of our strategy is first described, then, our implemented computing algorithms are explained. Recommendations and examples about the significant parameters for dealing with the measurement process are given, and finally several measurements are performed to validate the proposed method.
\end{abstract}

Keyword: Electromagnetic Compatibility (EMC), Electromagnetic Interference (EMI), Digital Signal Processing (DSP), Sound Card, Maritime Radiocommunications.

\section{INTRODUCTION}

Any metallic vessel behaves like a Faraday cage from which the radiation generated on board will probably remain on the ship and this situation will increase the possibility of EMC problems [1, 2]. On board the vessel there are a lot of radio-communication and radio-navigation equipment $[3,4]$ including VHF, HF, UHF communication transmitters, Xband, S-band Radar, satellite communications transmitters, Automatic Identification system (AIS), among others. This equipment emits electromagnetic radiation during their normal operation; in this case we are talking about on-board intentional electromagnetic radiation i.e. emissions. Moreover, inside the ship we can find many devices and apparatus like the air conditioning equipment, machinery being powered by motors, generators to operate tools, inverters, computers, printers, vacuum cleaners, washing machine, etc. These devices can emit non-intentional electromagnetic radiation during their normal function. Each device installed on the ship must comply with the current regulations, but when numerous electrical and electronic apparatus and equipment on board are working together in the vicinity, this leads to the creation of a hostile electromagnetic environment [2].

In a medium or large size warship, at least a spectrum analyzer is used for monitoring the radio-link quality for HF, VHF or UHF, even apart from the sensitive equipment Electronic Warfare (EW) or SIGnals INTelligence (SIGINT), which cannot be displaced by the ship given its size and weight characteristics. However, on civilian vessels, the only tool for detecting a malfunction or interference is the LF-HF receiver. Assuming that on-board the ship there is, a Radio official who knows what to do, a portable receiver, and a portable antenna, which is highly improbable since it came into full force on the 1999 "Global Maritime Distress and Safety System" GMDSS [5], when such officers were landed, and just until 1 February 1999 were part of the cadres of minimum crew of the ship since the radio was invented, becoming now a maintenance staff at ground stations or companies of the ports.

Thus, and particularly when on-board there is no calibrated equipment for spectrum analysis, it is necessary to resort to the ingenuity and symbiosis between electronic and computer sciences, to detect, locate and if possible identify the sources of noise and interference that cause malfunctions in the rest of the ship's equipment. The availability of a reliable software, known, expandable and intuitive, with VLF-UHF receiver, weighing less than one kilogram and that can be powered with batteries will be one of the best tools available for the electrotechnical officer of the ship, department staff of machinery with Radio-electronic training, as provide the Manila Amendments (2010) for the on training, certification, and watch-keeping for the seafarers signed by hundred of International Maritime Organization (IMO) members [6]. For this purpose, we developed various autonomous algorithms running in a parallel way, and making up, in the whole, a new low cost electromagnetic compatibility (EMC) measurement and identification system for ships (Figure 1). First, we design algorithms for controlling the IC-PCR1000 [7] receiver for the task of receiving signals in the band above $10 \mathrm{kHz}$. It is a wide band receiver that covers the frequency from $10 \mathrm{kHz}$ to 1300 $\mathrm{MHz}$, with different reception modes (AM, FM, FM-W, CW, LSB, and USB) (Table I). The IC-PCR1000 is connected to the PC sound card, leading to a powerful low cost system for signals analysis and measurement [8]. Second, we compute the low-level programming for the PC sound card in order to capture the signal received by the IC-PCR1000 for their further processing. The sound card has been used in several applications in the last years [15-21]. In most of the cases, sound card was used at the high-level programming, using some pre-existing tools and library available in software like Labview and Matlab. The sound card has a very good 
capability, but it is necessary to compute the low-level programming, in order to control the parameters which affect the capturing process. To our knowledge, this task has not been explored previously. Third, we program various algorithms; for the calculation of the signal spectrum [9], for the signal analysis [10], for the Digital Signal Processing [11], for measuring the signal detected $[12,13,14]$. Fourth, we build a visual interface for the control and data displays of the system measurement. Last, we create a strategy to save data into a data base containing the relevant information.

The task of measuring signals and detecting Electromagnetic interferences (EMI) require understanding of several factors $[22,23]$. From one side, it is necessary to know the nature of the interference we are looking for, the frequency range of these interferences, the adequate antenna [24], cables and connectors to be used. From the other side, we must recognize which bandwidth (BW) filter must be applied, when it is necessary to use the averaging techniques and what type is appropriate, how many data samples must be captured, what sampling frequency should be selected, how many FFT points must be calculated, what is the optimal buffer size, and other important parameters. Changing one of these parameters will affect the whole measurement process. Each of these factors requires special consideration.

\section{SYSTEM DESCRIPTION}

The basic scheme for the system measurement is represented in Fig. 1. Next we describe each stage of the system.

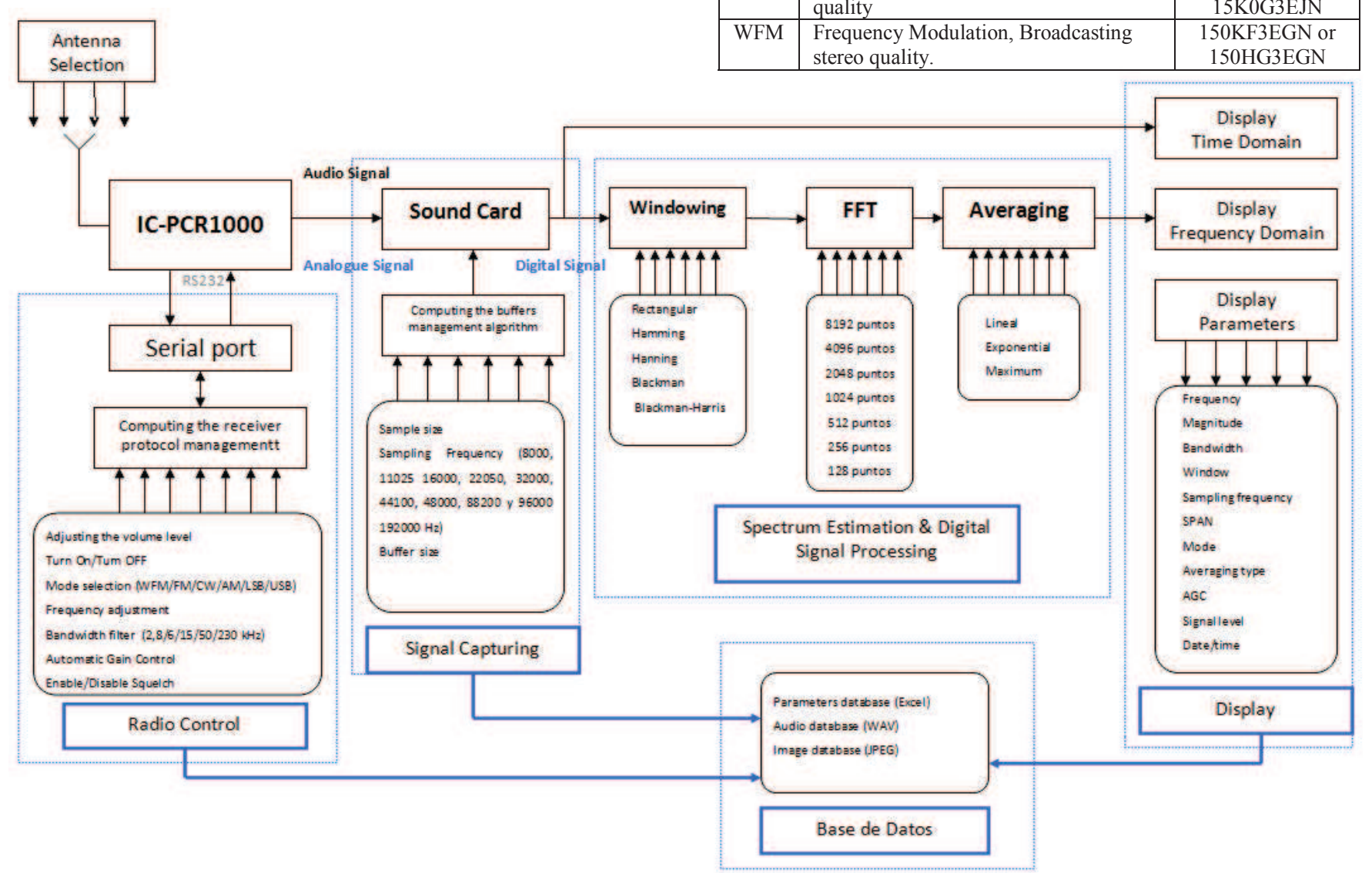

Figure 1. The basic scheme for the system measurement developed

\section{A. Radio Control}

The IC-PCR-1000 (Fig. 2) is a wideband radio receiver that is controlled via the $\mathrm{PC}$ serial port. It has wideband coverage from $10 \mathrm{kHz}$ to $1.3 \mathrm{GHz}$ and can operate at CW, LSB, USB, AM, FM and WFM mode (Table I). This receiver will be our primary interface with radio-frequencies. We will use the audio output to have an intermediate frequency on which will perform the spectral analysis by the next stages. So, we will have a maximum bandwidth of $20 \mathrm{kHz}$.

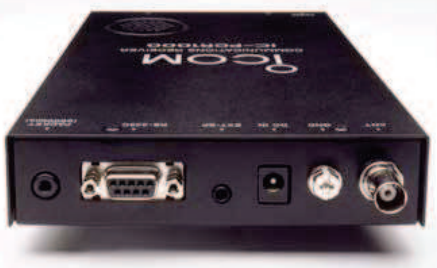

Figure 2. IC-PCR1000 receiver

TABLE I

IC-PCR1000 RECEPTION MODE

\begin{tabular}{|c|l|c|}
\hline $\begin{array}{c}\text { RX } \\
\text { mode }\end{array}$ & \multicolumn{1}{|c|}{ Description } & $\begin{array}{c}\text { Compatible } \\
\text { Emission class }\end{array}$ \\
\hline AM & $\begin{array}{l}\text { Amplitude Modulation Double } \\
\text { Sideband }\end{array}$ & 6 K00A3EJN \\
\hline USB & $\begin{array}{l}\text { Superior Single Side Band (SSB) with } \\
\text { suppressed carrier (Analog Phony) }\end{array}$ & 2 K70J3EJN \\
\hline LSB & $\begin{array}{l}\text { Inferior Single Side Band (SSB) with } \\
\text { suppressed carrier (Analog Phony) }\end{array}$ & 2 K70J3EJN \\
\hline CW & Carrier interruption Telegraphy & $\begin{array}{c}\text { 1K00A1AAN or } \\
1 \mathrm{~K} 00 J 2 A A N\end{array}$ \\
\hline FM & $\begin{array}{l}\text { Frequency Modulation, commercial } \\
\text { quality }\end{array}$ & $\begin{array}{c}15 \mathrm{~K} 0 \mathrm{~F} 3 \mathrm{EJN} \text { or } \\
15 \mathrm{~K} 0 \mathrm{G} 3 \mathrm{EJN}\end{array}$ \\
\hline WFM & $\begin{array}{l}\text { Frequency Modulation, Broadcasting } \\
\text { stereo quality. }\end{array}$ & $\begin{array}{c}150 \mathrm{KF} 3 \mathrm{EGN} \text { or } \\
150 \mathrm{HG} 3 \mathrm{EGN}\end{array}$ \\
\hline
\end{tabular}


Opening the serial port device
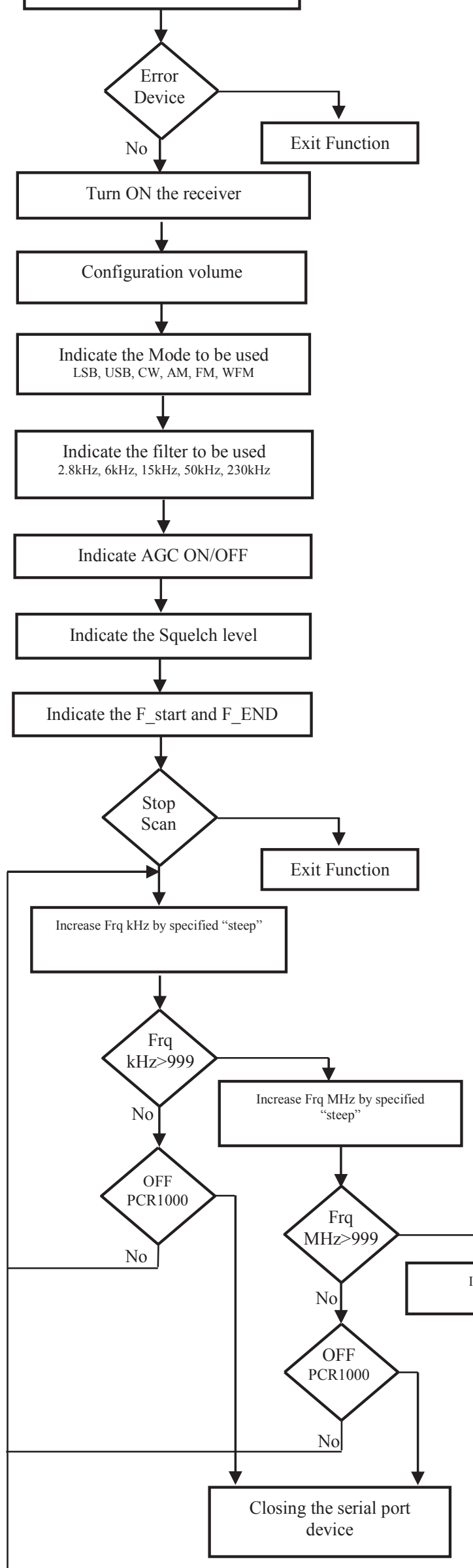

For example, we have implemented a monitoring system algorithm for scanning some important maritime frequencies and when detecting emission at these specific bands, the system triggers an alarm, saves the detected events in a data base with information of the time, level of the signal, frequency, etc. In addition we store the image of the spectrum for further analysis. This algorithm is described in Figure 3.

\section{B. Signal Capturing}

The signal received by the IC-PCR 1000 is a continuous signal $x(t)$. This signal will be sampled into a sequence of a discrete data $x[n]$ (EQ1). This periodic sampling is achieved by using the PC-sound card. For this purpose, we compute a low-level programming algorithm in order to control the tasks of capturing signal, and buffers management to store data in the optimal way without losing information.

$$
X_{N}=\sum_{n=0}^{N-1} x[n]
$$

Several implementations can be used to capture the signal using the sound card. Nowadays, advanced techniques known as - simultaneous multi-buffer acquisition and readout (SAR) mode [22] are used to improve the precision of the capturing method with no information loss, especially used in the case of measuring pulse that can appear in a very short time. In our application we use the double buffering technique. It consists of using two buffers in order to achieve the processes of continuous capturing without loss of data.

While one buffer is capturing data, the other is making the processing task. This process is described in Fig. 4.

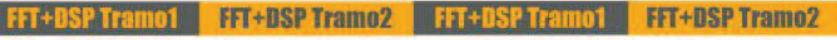

Figure 4. Capturing process protocol used

The algorithm implementation for computing the buffers management is shown in the Fig. 5.

\section{Spectrum estimation \& Digital signal processing}

The discrete-time signal $\mathrm{X}_{\mathrm{N}}(1)$ is then converted from the time domain to the frequency domain though the calculation of the Discrete Fourier Transform DFT (2) [10-12]. We compute the DFT by the Fast Fourier Transform (FFT) algorithm [26-29].

$$
X(m)=\sum_{n=0}^{N-1} x(n) e^{-2 \pi n m / N}
$$

Where:

$X(m)$ : discrete Fourier Transform of $x(n)$ $\mathrm{m}$ : index DFT output at the frequency domain, $\mathrm{m}=0,1,2, \ldots, \mathrm{N}-1$

$\mathrm{x}(\mathrm{n})$ : samples of time input waveform $\mathrm{x}(0)$, $\mathrm{x}(1), \mathrm{x}(2), \ldots, \mathrm{x}(\mathrm{n})$

$n$ : index sample of the signal of time input

$\mathrm{N}$ : total number of the input samples.

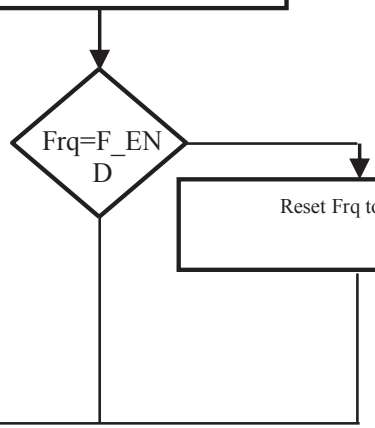

Figure 3. Monitoring system algorithm flowchart for IC-PCR1000 scanning 


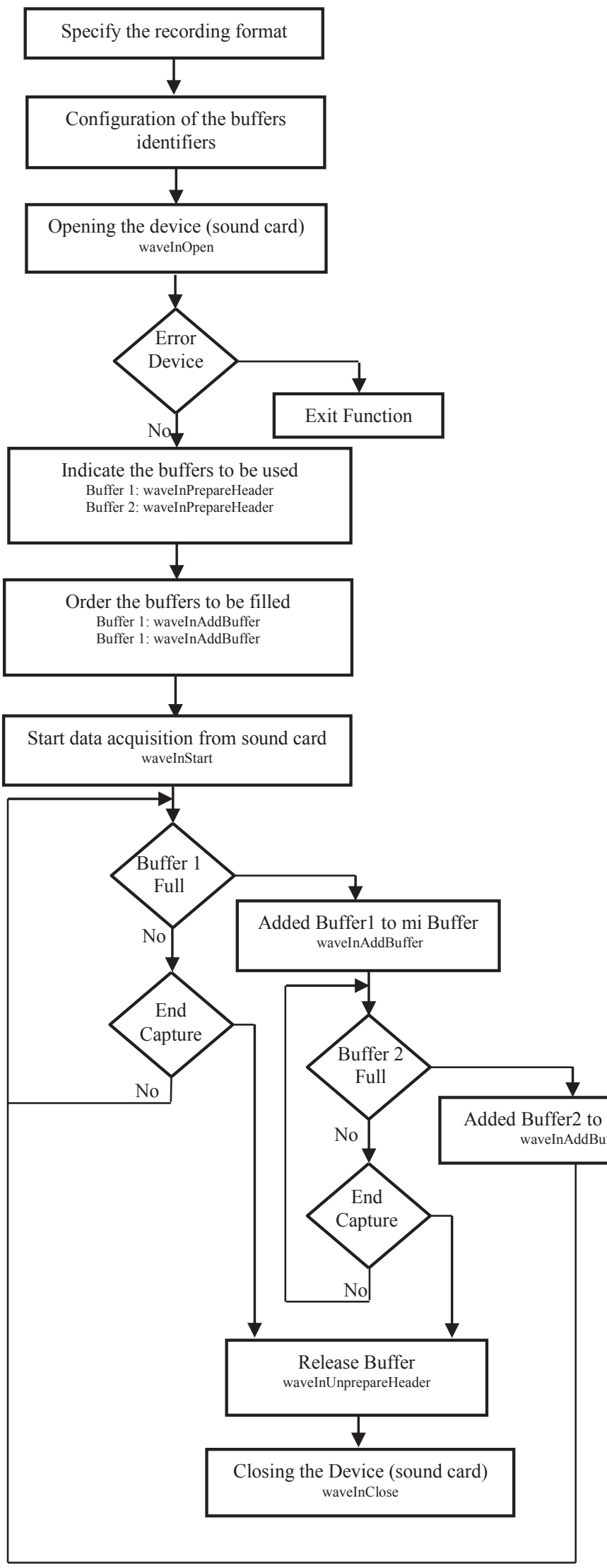

Figure 5. The buffers management algorithm flowchart
In order to reduce the leakage effect we use the windowing technique. The input sequence $\mathrm{X}_{\mathrm{N}}(1)$ is multiplied by a function window w(n) (4-9) before the DFT is performed.

$$
X_{w}(m)=\sum_{n=0}^{N-1} w(n) \cdot x(n) e^{-j 2 \pi n m / N}
$$

The windows implemented in our measurement system are presented bellow.

Rectangular window:

$$
w(n)=1 \text { for } \quad n=0,1,2, \ldots, N-1 \quad \text { (4) }
$$

Triangular window:

$$
w(n)=\left\{\begin{array}{lcc}
\frac{n}{N / 2} & & \text { for } \quad n=0,1,2, \ldots, N / 2 \text { (5) } \\
2-\frac{n}{N / 2} & \text { for } & n=N / 2+1, N / 2+2, \ldots, N-1
\end{array}\right.
$$

Hanning window:

$w(n)=0.5-0.5 \cos \left(\frac{2 \pi n}{N}\right)$ for $\quad n=0,1,2, \ldots, N-1$

Hamming window:

$w(n)=0.54-0.46 \cos \left(\frac{2 \pi n}{N}\right)$ for $\quad n=0,1,2, \ldots, N-1$

Blackman window:

$$
\begin{aligned}
& w(n)=0.42-0.5 \cos \left(\frac{2 \pi n}{N}\right)+0.08 \cos \left(\frac{4 \pi n}{N}\right) \\
& \text { for } \quad n=0,1,2, \ldots, N-1 \quad \text { (8) }
\end{aligned}
$$

Blackman-Harris window:

$$
\begin{aligned}
& w(n)=0.36-0.49 \cos \left(\frac{2 \pi n}{N}\right)+0.14 \cos \left(\frac{4 \pi n}{N}\right)-0.01 \cos \left(\frac{6 \pi n}{N}\right) \\
& \text { for } \quad n=0,1,2, \ldots, N-1 \quad \text { (9) }
\end{aligned}
$$

Applying a window reduces the leakage effect, but at the same time reduces the magnitude of the output, for this reason, it is necessary to multiply the output magnitude DFT value by a scaling factor [30, 31]. Table II shows the different scaling factor values for the different windows used in our measurement system.
TABLE II

DIFFERENT SCALING FACTOR FOR THE DIFFERENT WINDOW

\begin{tabular}{|c|c|}
\hline Window & Scaling Factor \\
\hline Rectangular & 1 \\
\hline Hamming & 0.54 \\
\hline Blackman & 0.42 \\
\hline Blackman-Harris & 0.42 \\
\hline Hanning & 0.50 \\
\hline
\end{tabular}

\section{EXPERIMENTAL RESULT}

\section{A. Reducing the effect of noise}

When the level of the signal to be detected is nearly equal to the noise level, it is difficult to extract this signal from noise. Especially when using the receiver. In order to improve the accuracy and repeatability of measurements we give some recommendations for this purpose. 


\section{A.1. Measurement in narrow band}

Doing measurement in narrow band (NB) mode is one way of reducing the quantity of the background noise mixed with the signal (Fig. 6), so we can identify the signal of interest better when we choose a narrower filter.

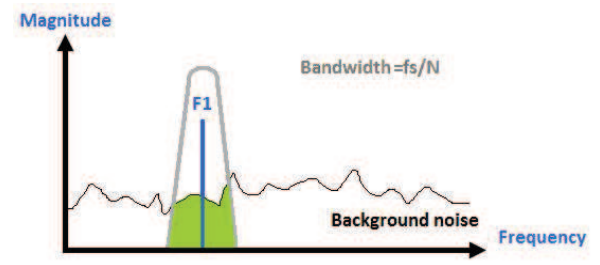

(a)

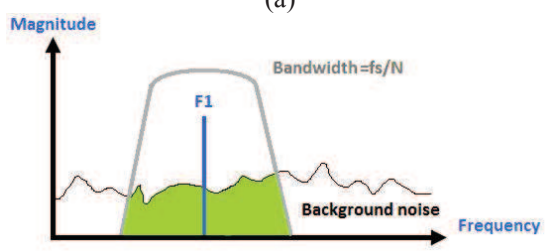

(b)

Figure 6. Quantity of noise included in (a) NB measurement (b) WB measurement

\section{A.2. Increasing the size of the number of points FFT}

Increasing the size of the number of points FFT to be computed has the advantage of increasing the processing gain [11], which allows for the possibility of extracting signal that is inserted into noise.

The output signal-to-noise ratio (SNR) of the DFT increases when the number of points FFT computed increase. In [8] several examples were presented to show this effect. The FFT act like a digital filter, the higher the FFT size is, the lower is the background noise included; the narrower is the main lobe of the signal to be detected.

\section{A.3. Averaging}

We give example of implementation of the technique of Exponentially Weighted Moving Average (EWMA) [32, 33] which is a statistical method to monitor the data averaging process, giving more weight to the latest data, but at the same time take into account the effect of the older data.

The EWMA is expressed in terms of the averaging calculated in the previous period using the following equation:

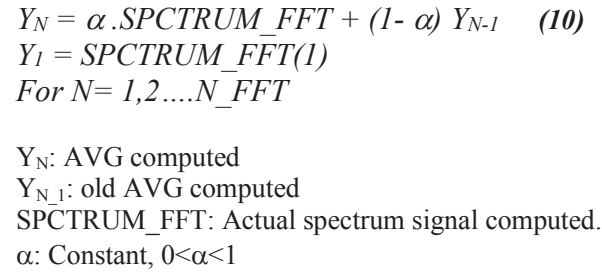

Each calculation of the exponential moving average adds the effect of the latest data without ignoring the old one.

The equation (10) can be written in a different way (11) to emphasis that the exponential moving average tends to retain its previous values and only update by a fraction of its difference from the most recent data.

$$
\begin{aligned}
& Y_{N}=Y_{N-1}+\alpha .\left(S P C T R U M_{-} F F T-Y_{N-1}\right) \\
& Y_{I}=S P C T R U M_{-} F F T(1) \\
& \text { For } N=1,2 \ldots . . . F F T
\end{aligned}
$$

The EWMA initialization value can be Y1= Spectrum_FFT (1). It is possible also to choose other value like the Spectrum_FFT (2) or Spectrum_FFT (3), etc. The effect of Y1 initialization in EWMA calculation will also depend on the constant $\alpha$. The more $\alpha$ increases, the lower is the impact of the oldest capture.

\section{B. Method performance evaluation}

Obtained specifications with the method described in this work are shown in Table III-VI.

As we can see in Table IV and Table $\mathrm{V}$ which represent the sensitivity of the IC-PCR1000 and the sound card respectively, with the sound card IEEE-32 bits configuration, and the IC-PCR1000 in SSB mode we obtain impressive sensitivity, which is one of the advantages of our method. Another advantage presented by our method is the possibility to measure narrow band signals (Table. III) This kind of measurement is very important in case of having signals very close and could be detected as a unique signal if the selectivity of the measurement instrument is not narrow enough (Fig. 7). A Comparison between the minimum specifications for a precompliance spectrum analyzer [13] and the characteristics of our method is shown in Table VI. As we can see, the total specification for our system, present an excellent capabilities.

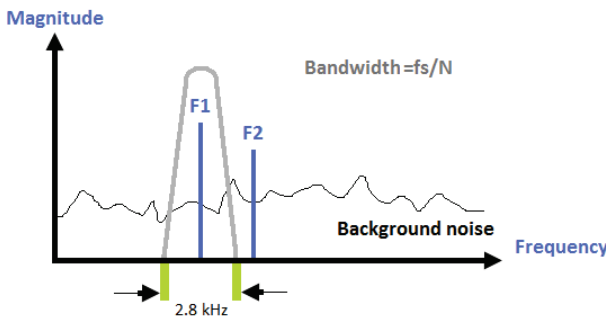

Figure 7. Narrow band measurement signals

TABLE III IC-PCR1000 FILTER BANDWIDTH

\begin{tabular}{|c|c|}
\hline $\begin{array}{c}\text { Modes of } \\
\text { reception }\end{array}$ & Bandwidth \\
\hline AM & $15 / 6 \mathrm{kHz}$ \\
\hline SSB & $2.8 \mathrm{kHz}$ \\
\hline $\mathrm{CW}$ & $2.8 \mathrm{kHz}$ \\
\hline FM-Narrow & $15 / 6 \mathrm{kHz}$ \\
\hline FM-Wide & $230 \mathrm{kHz}$ \\
\hline
\end{tabular}

TABLE IV

IC-PCR1000 SENSITIVITY

\begin{tabular}{|c|c|c|c|c|}
\hline $\begin{array}{c}\text { Frequency } \\
(\mathrm{MHz})\end{array}$ & $\begin{array}{c}\text { SSB/CW } \\
2.8 \mathrm{kHz} \text { filter } \\
(10 \mathrm{~dB} \mathrm{~S} / \mathrm{N}) \\
\mathrm{dB} \mu \mathrm{V}\end{array}$ & $\begin{array}{c}\text { AM } \\
6 \mathrm{kHz} \text { filter } \\
(10 \mathrm{~dB} \mathrm{~S} / \mathrm{N}) \\
\mathrm{dB} \mu \mathrm{V}\end{array}$ & $\begin{array}{c}\text { FM } \\
15 \mathrm{kHz} \text { filter } \\
(12 \mathrm{~dB} \text { SINAD }) \\
\mathrm{dB} \mu \mathrm{V}\end{array}$ & $\begin{array}{c}\text { WFM } \\
230 \mathrm{kHz} \text { filter } \\
(12 \mathrm{~dB} \text { SINAD }) \\
\mathrm{dB} \mu \mathrm{V}\end{array}$ \\
\hline $0.5-1.8$ & -5.04 & 7.96 & -- & -- \\
\hline $1.8-28$ & -11.1 & 2.92 & -- & -- \\
\hline $28-30$ & -11.1 & 2.92 & -6.02 & -- \\
\hline $30-50$ & -9.12 & 5.11 & -6.02 & -- \\
\hline $50-700$ & -14.0 & 0.00 & -9.90 & -2.05 \\
\hline $700-1300$ & -12.0 & 2.28 & -7.96 & 0.00 \\
\hline
\end{tabular}


TABLE V

SOUND CARD SENSITIVITY

\begin{tabular}{|c|c|c|}
\hline \multicolumn{2}{|c|}{ SOUND CARD SENSITIVITY } \\
\hline 8 bits & $3.9215 \mathrm{mV}$ & $71.9 \mathrm{~dB} \mu \mathrm{V}$ \\
\hline 16 bits & $12,207 \mu \mathrm{V}$ & $21.6 \mathrm{~dB} \mu \mathrm{V}$ \\
\hline 24 bits & $0.0596 \mu \mathrm{V}$ & $-24.5 \mathrm{~dB} \mu \mathrm{V}$ \\
\hline IEEE-32 bits & $0,00023 \mu \mathrm{V}$ & $-72,65 \mathrm{~dB} \mu \mathrm{V}$ \\
\hline
\end{tabular}

TABLE VI

COMPARISON BETWEEN THE MINIMUM SPECIFICATIONS FOR A PRECOMPLIANCE SPECTRUM ANALYZER AND THE CHARACTERISTICS OF OUR METHOD

\begin{tabular}{|c|c|c|c|c|}
\hline Parameter & $\begin{array}{l}\text { Precompliance } \\
\text { Specification }\end{array}$ & $\begin{array}{l}\text { IC-PCR1000 } \\
\text { Specification }\end{array}$ & $\begin{array}{l}\text { Sound Card } \\
\text { Specification }\end{array}$ & $\begin{array}{l}\text { System Total } \\
\text { Specification }\end{array}$ \\
\hline $\begin{array}{l}\text { Frequency } \\
\text { range }\end{array}$ & $\begin{array}{c}100 \mathrm{kHz}- \\
1 \mathrm{GHz}\end{array}$ & $\begin{array}{c}10 \mathrm{kHz} \text { to } 1300 \\
\mathrm{MHz}\end{array}$ & $\begin{array}{c}50 \mathrm{~Hz} \text { to } \\
20 \mathrm{kHz}\end{array}$ & $\begin{array}{c}50 \mathrm{~Hz} \text { to } 1300 \\
\mathrm{MHz}\end{array}$ \\
\hline $\begin{array}{l}\text { Resolution } \\
\text { IF } \\
\text { bandwidth }\end{array}$ & $\begin{array}{l}9 \text { or } 10 \mathrm{kHz} \text { and } \\
100 \text { or } 120 \mathrm{kHz}\end{array}$ & $\begin{array}{c}2.8 / 6 / 15 / 50 / 230 \\
\mathrm{kHz}\end{array}$ & $\begin{array}{c}1 \mathrm{~Hz}-374 \\
\mathrm{~Hz}\end{array}$ & $\begin{array}{c}2.8 / 6 / 15 / 50 / 230 \\
\mathrm{kHz} \text { by Hw } \\
1 \mathrm{~Hz}-374 \mathrm{~Hz} \\
\text { by } \mathrm{Sw}\end{array}$ \\
\hline $\begin{array}{l}\text { Detector } \\
\text { functions }\end{array}$ & $\begin{array}{l}\text { Peak and } \\
\text { average }\end{array}$ & - & - & $\begin{array}{c}\text { Peak and } \\
\text { average } \\
\text { AVG EXP }\end{array}$ \\
\hline \multirow{3}{*}{ Sensitivity } & \multirow{3}{*}{$\begin{array}{c}<20 \mathrm{~dB} \mu \mathrm{V} \text { at } \\
100 \mathrm{kHz} \\
\text { Bandwidth }\end{array}$} & \multirow{3}{*}{$\begin{array}{c}<0 \mathrm{~dB} \mu \mathrm{V} \text { at } \\
230 \mathrm{kHz} \\
\text { Bandwidth } \\
<-5.04 \mathrm{~dB} \mu \mathrm{V} \text { at } \\
2.8 \mathrm{kHz} \\
\text { Bandwidth }\end{array}$} & \multirow{3}{*}{$-72,65 \mathrm{~dB} \mu \mathrm{V}$} & $\begin{array}{l}-72,65 \mathrm{~dB} \mu \mathrm{V} \\
\text { for frequency } \\
\quad<20 \mathrm{kHz}\end{array}$ \\
\hline & & & & $\begin{array}{c}<0 \mathrm{~dB} \mu \mathrm{V} \text { at } \\
230 \mathrm{kHz} \\
\text { Bandwidth }\end{array}$ \\
\hline & & & & $\begin{array}{c}<-5.04 \mathrm{~dB} \mu \mathrm{V} \text { at } \\
2.8 \mathrm{kHz} \\
\text { Bandwidth }\end{array}$ \\
\hline Display & $\begin{array}{c}\text { Free run and } \\
\text { max-hold } \\
\text { modes }\end{array}$ & $\begin{array}{c}\text { Free run and } \\
\text { max-hold } \\
\text { modes }\end{array}$ & $\begin{array}{c}\text { Free run and } \\
\text { max-hold } \\
\text { modes }\end{array}$ & $\begin{array}{c}\text { Free run and } \\
\text { max-hold } \\
\text { modes }\end{array}$ \\
\hline $\begin{array}{c}\text { Input } \\
\text { impedance }\end{array}$ & $50 \Omega$ & $50 \Omega$ & - & $50 \Omega$ \\
\hline
\end{tabular}

We have tested the Analog to Digital Converter (ADC) errors of the sound card, and have found a good linearity (Fig.8), an offset error which is corrected by software through an initial calibration before starting the measurement process.

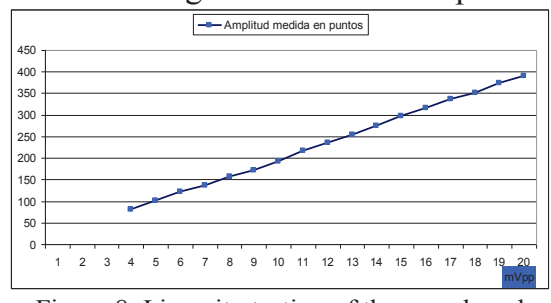

Figure 8. Linearity testing of the sound card

For the frequency and amplitude calibration we used the Agilent 33250A waveform generator.

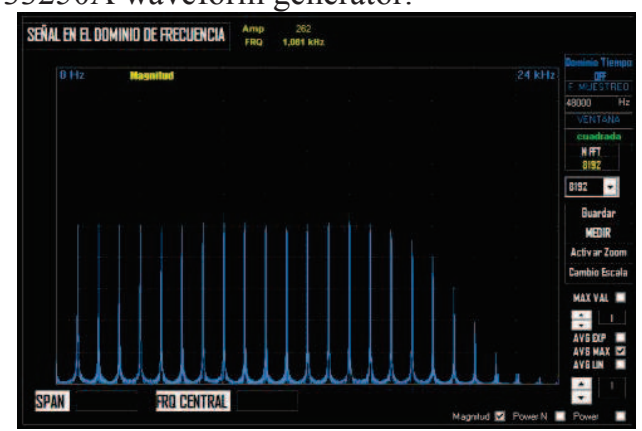

Figure 9. Frequency Calibration process
We give an example of signal detection and measurement by our method. We use a radio-telephone BAOFENG VHF/UHF in order to emit a VHF signal with frequency $144,010 \mathrm{MHz}$ in FM-Narrow mode, with a low power. We tune the ICPCR1000 receiver to the frequency $144,007 \mathrm{MHz}$; we use the LSB reception mode, with a filter BW $15 \mathrm{kHz}$. The parameters of the analysis used are: Sampling Frequency Fs $=44,1 \mathrm{kHz}$. N_FFT=8192, Window: Hanning. The Fig. 10 shows the spectrum of the frequency $144,007 \mathrm{HMz}$ when no emission was made from the BAOFENG VHF/UHF radiotelephone.

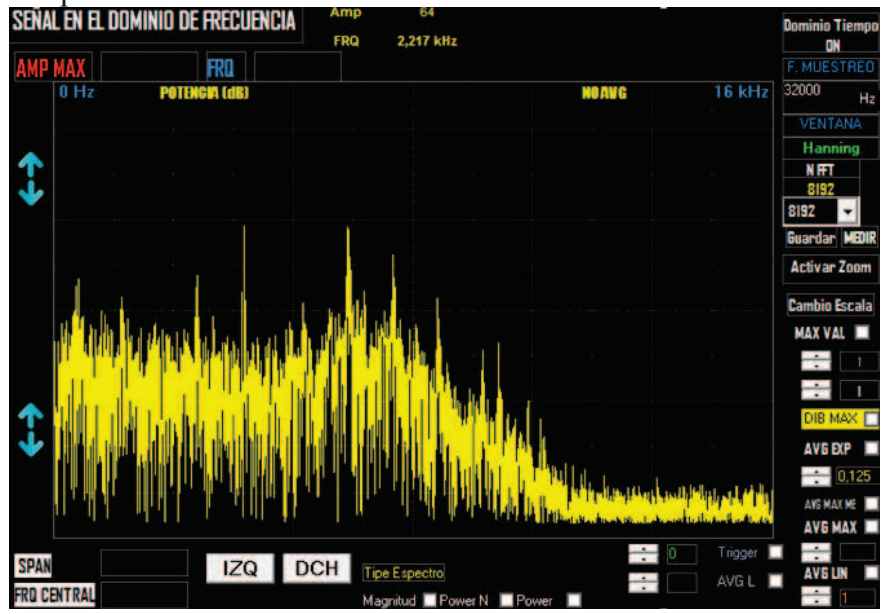

Figure 10. Spectrum of the frequency 144,007 HMz when no emission from the BAOFENG VHF/UHF radio-telephone

The Fig.11 depicts the spectrum detected by our method measurement when an emission is sent from the BAOFENG VHF/UHF radio-telephone.

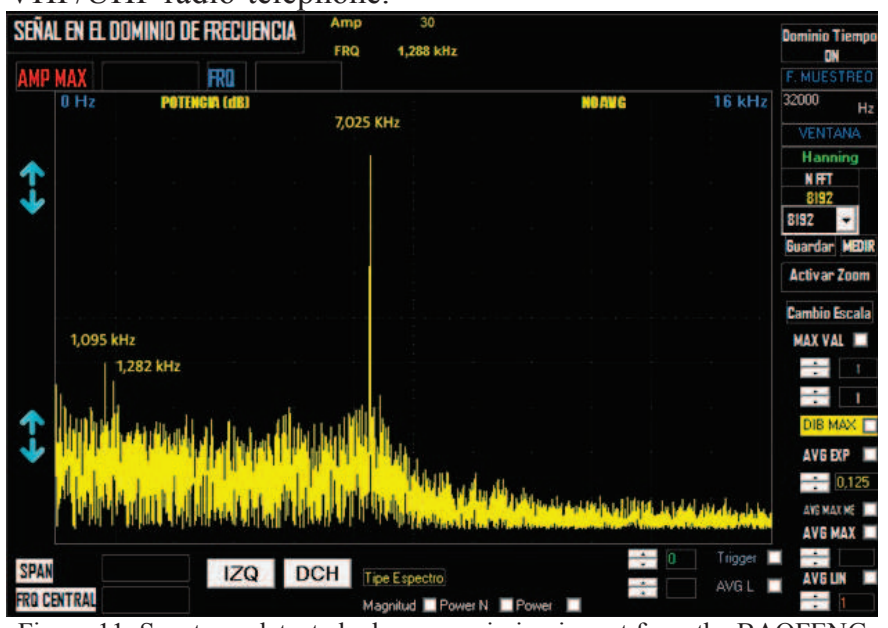

Figure 11. Spectrum detected when an emission is sent from the BAOFENG VHF/UHF radio-telephone

The next example (Fig.12) shows the measurement of a radiated known AM signal sent from the PCE-SDG1010 waveform generator. We use the AN200 E1-124819 Eton $(520 \mathrm{kHz}-1710 \mathrm{kHz})$ antenna for the emission of the signal $550 \mathrm{kHz}$ modulated with $5 \mathrm{kHz}$.

To detect this signal we use the following parameters: Frequency reception $550 \mathrm{kHz}$, mode AM, BW $15 \mathrm{kHz}$, 


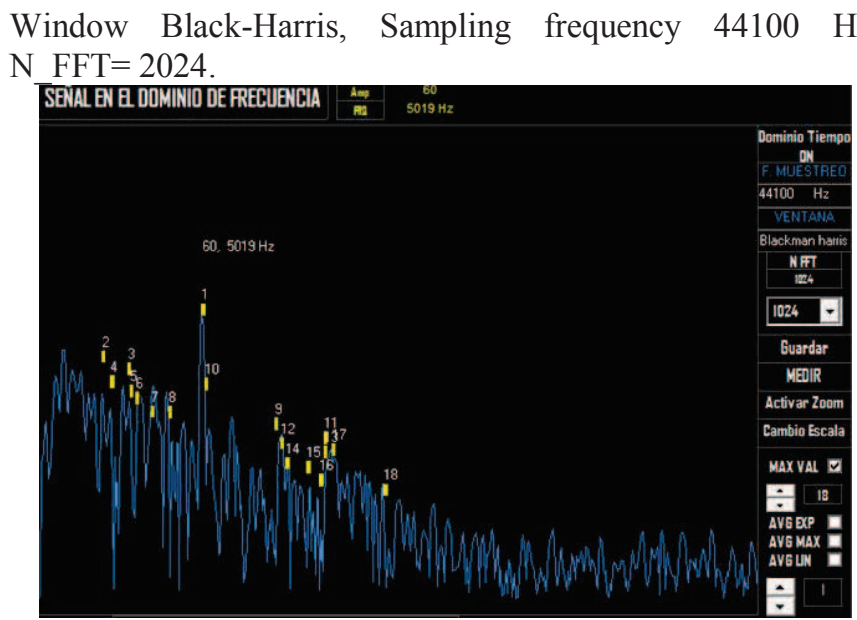

Figure 12. Measurement of a radiated AM signal

\section{CONCLUSION}

In this paper, the design of simple low cost electromagnetic compatibility (EMC) measurement and verification system for ships was presented. We programmed all the algorithms for the systems, in order to have reliable software, known, expandable and intuitive, in combination with a VLF-UHF receiver. The method has a remarkable performance which is summarized in TABLE VI. Some measurements were conducted to illustrate method capabilities.

\section{REFERENCES}

[1] L. Preston E., "Shipboard Electromagnetics" Artech House, Inc, 1987.

[2] Bakkali, M.; Mascarenas, C. \& All, "Feasibility study of advancing and sitting up Power Line Communication (PLC) system under Environment of Electromagnetic Compatibility (EMC) into the ships," Electrical Power Quality and Utilization, 2007. EPQU 2007. 9th International Conference on, vol., no., pp.1,5, 9-11 Oct. 2007.

[3] G. D. LEES and W. G. WILLIAMSON , Handbook for Marine Radio Communication, LLoyd's Of London Press LTD, Great Britain, 1993.

[4] C Mascareñas y Pérez-Íñigo, "Manual Básico de Sistemas de Comunicaciones Marítimas", Universidad de Cádiz.

[5] Manual on the Global Maritime Distress and Safety System (GMDSS), International Maritime Organization (IMO), Switzerland, 2007.

[6] Unión Internacional de Telecomunicaciones, "Manual para uso de los servicios móvil marítimo y móvil marítimo por satélite", Edición español 1999, Oficina de radiocomunicaciones.

[7] M. Bakkali, C. Mascareñas-Perez-Iñigo, and R. Carmona-Galan, "ICPCR1000 Control Using a Wireless Sensor Network (WSN)", International Journal of Computer and Communication Engineering, Vol. 1, No. 3, September 2012

[8] M. BAKKALI , C. MASCAREÑAS-PEREZ-IÑIGO, "Real Time Digital Signal Analysis and Measurement", Proc. of the Intl. Conf. on Advances in Computing, Electronics and Communication-- ACEC 2013, institute of Research Engineers and Doctors.

[9] Robinson, E.A., "A historical perspective of spectrum estimation," Proceedings of the IEEE, vol.70, no.9, pp. 885-907, Sept. 1982

[10] A. Papoulis, "Signal Analysis" McGraw-Hill Book Company, New York, 1977, ISBN. 0-07-048460-0

[11] Richard G. Lyons, Understanding Digital Signal Processing, Pearson Education, 2010, 0137028520
[12] Robert A. Witte, Electronic Test Instruments. Theory and Applications, Hewlett=Packard, New Jersey, 1993

[13] W. Ott Henry, Electromagnetic Compatibility Engineering, Sep 2009, ISBN: 978-0-470-18930-6

[14] Emisiones Radioeléctricas: Normativa, Técnicas de Medida y Protocolos de Certificación, COLEGIO OFICIAL DE INGENIEROS DE TELECOMUNICACION, Catedra coit (etsit-Upm)

[15] Xiaoli Quan; Nanquan Zhou; Haotian Wu, "Design of sound card electrocardiosignal acquisition system based on LabVIEW," Multimedia Technology (ICMT), 2011 International Conference on pp.282,285, 2628 July 2011

[16] Zixin Zhao; Shuxiang Guo, "Development of an acoustic communication system for multiuser based on sound card," Complex Medical Engineering (CME), 2011 IEEE/ICME International Conference on pp.264,267, 22-25 May 2011

[17] Gunawan, T.S.; Khalifa, O.O., "PC sound card based instrumentation and control," Computer and Communication Engineering (ICCCE), 2010 International Conference on , vol., no., pp.1,4, 11-12 May 2010.

[18] Zhao Xian-ling, "The Virtual Instrument Based on Labview and Sound Card," Computational Aspects of Social Networks (CASoN), 2010 International Conference on , vol., no., pp.743,745, 26-28 Sept. 2010.

[19] Xu Xin-sheng; and All, "Study on precise frequency measurement based on sound card," Electronic Measurement \& Instruments, 2009. ICEMI '09. 9th International Conference on, vol., no., pp.2-455,2-458, 16-19 Aug. 2009

[20] Aiju Chen; Jingjing Liu, "A Kind of Virtual Oscilloscope Used in Experiment Teaching Based on Sound Card and LabVIEW," Education Technology and Training, 2009. ETT '09. Second International Conference on , vol., no., pp.118,121, 13-14 Dec. 2009

[21] Neitzert, H.C.; Rainone, N.G., "Photocurrent and electroluminescence mapping system for optoelectronic device characterization using a PC sound card for data acquisition," Instrumentation and Measurement Technology Conference Proceedings, 2007. IMTC 2007. IEEE, vol., no., pp.1,6, 1-3 May 2007.

[22] Aerospace \& Defense Symposium 2012, Agilent Technologies, 31/05/2012, Madrid, Spain

[23] J. Balcello, F. Daura, R. Esparza, R. Pallás, Interferencias Electromagneticas en sistemas electrónicos, ISBN 84-267-0841-2

[24] Preston E. LAW JR., "Shipboard Antennas", 2nd edition ISBN: 089006-211-0, Arthech house inc. 1986

[25] S.W. Smith; The Scientist and Engineer's Guide to Digital Signal Processing, California Technical Publishing, 1997, ISBN 0966017633

[26] J.W. Cooley and J.W. Tukey, "An algorithm for the machine calculation of complex Fourier Series," Mathematics Computation, Vol. 19, 1965, pp 297-301

[27] HV Sorensen and all, Real Valued Fast Fourier Transform Algorithms, IEEE Transactions on acoustics, speech, and signal processing, VOL. ASSP-35, NO. 6, June 1987

[28] J. A GLASSMAN, "A generalization of the fast Fourier transform" IEEE Transactions on computers, VOL. C19, NO. 2, February 1970

[29] GD Bergland, "A guided tour of the fast Fourier transforms," IEEE Spectrum, vol. 6, pp. 41-52, July 1969

[30] Harris, F.J., "On the use of windows for harmonic analysis with the discrete Fourier transform," Proceedings of the IEEE , vol.66, no.1, pp.51,83, Jan. 1978

[31] Solomon, O., Jr., "The use of DFT windows in signal-to-noise ratio and harmonic distortion computations," Instrumentation and Measurement, IEEE Transactions on, vol.43, no.2, pp.194,199, Apr 1994

[32] Roberts, S.W. (1959) "Control Chert Tests Based on Geometric Moving Averages", Technometrics, 1, 239-250

[33] Lucas, J. M. and Saccucci, M. S. (1990). "Exponentially weighted moving average control schemes: Properties and enhancements", Technometrics 32, 1-29. 